\title{
CORRESPONDENCE
}

\section{Ovarian Cancer: Diagnosis and Treatment}

by Dr. med. Alexander Burges, Prof. Dr. med. Barbara Schmalfeldt in volume $38 / 2011$

\section{Ovarian Cancer: Diagnosis and Treatment}

We wish to mention three studies that advocate better prevention of ovarian cancer, since the disease is fatal in six of 10 affected women after several years $(9600$ new cases and 5500 deaths every year).

- Early detection for a better prognosis by means of screening is not in sight, according to a randomized controlled study (1) of transvaginal ultrasound with tumor marker test CA 125 . The mortality in the screening group was 3.1 per 10000 women years; the rate achieved by usual preventive care measures was 2.6/10 000. Screening 20000 women would therefore lead to one less death due to ovarian cancer. The study investigated 80000 women over 12 years.

- A possible preventive intervention in women at high risk of being carriers of BRCA mutations is bilateral adnexectomy at age 30, for example. This would be associated with an acceleration of all aging processes by 20 years, with sequelae including osteoporosis, coronary heart disease, neurodegenerative disorders. For carriers of the BRCA1 mutation, a US study (2) calculated the following: castration at age 40 can be expected to result in a $15 \%$ higher total survival rate (absolute value) in the following 30 years of life. Even earlier castration would not entail any further reduction in the risk of cancer (2).

- This means that hormonal prevention of ovarian cancer is very important. In women taking the contraceptive pill for 10 years the cancer risk is reduced by $50 \%$. This also applies to BRCA carriers, who do not have a higher risk of breast cancer as a result. A meta-analysis of 15 studies (3) compared 2855 breast cancer patients with 2954 healthy carriers of the BRCA mutation. Such a positive study result could not be expected before 1975, when pill dosages were double the current amount. Nowadays, doctors mostly prescribe pills of $20 \mathrm{mg}$ ethinylestradiol, which can be used in the prevention of ovarian cancer. These co-indications of the contraceptive pill should be addressed in women at increased risk of ovarian cancer.

DOl: 10.3238/arztebl.2012.0208a

\section{REFERENCES}

1. Buys SS, et al.: Effect of screening on ovarian cancer mortality. JAMA 2001; 305: 2295-303.

2. Rebbeck TR, et al.: Breast cancer risk after bilateral prophylactic 00phorectomy in BRCA1 mutation carriers. Journal of the National Cancer Institute 1999; 9: 1475-9.
3. lodice S, et al.: Oral contraceptive use and breast or ovarian cancer risk in BRCA1/2 carriers: a meta-analysis. Eur J Cancer 2010; 46: 2275-84.

4. Burges A, Schmalfeldt A: Ovarian cancer: diagnosis and treatment Dtsch Arztebl Int 2011; 108(38): 635-41.

Prof. Dr. med. Dipl. Psych. J. M. Wenderlein

Universität Ulm, wenderlein@gmx.de

\section{Conflict of interest statement}

The author declares that no conflict of interest exists.

\section{In Reply:}

We thank the correspondent for mentioning the recent publication about the value of screening reported by Buys; the recently published Health Technology Assessment report 113 from the German Institute of Medical Knowledge and Information (Deutsches Institut für Medizinische Dokumentation und Information, DIMDI) (1) regarding individual health services also refers to this study.

Prophylactic adnexectomy in carriers of the BRCA mutation is recommended only for women older than 40 as the risk of developing ovarian cancer suddenly increases, whereas earlier oophorectomy seems to be associated with a rise in other disorders (2).

In our opinion, nothing conclusive can be said about hormone replacement therapy in carriers of the mutation. Short term therapy does not seem to have any negative effects on the risk of breast cancer (3).

Because of the contradictory conclusions reached by the meta-analyses with regard to the contraceptive pill and risk of breast cancer in women carrying the mutation, the consortium can currently not make any recommendation in favor of taking oral contraception (personal communication).

DOI: 10.3238/arztebl.2012.0208b

\section{REFERENCES}

1. Schnell-Inderst $P$, Hunger T, Hintringer $K$, et al.: HTA-Bericht 113. Individuelle Gesundheitsleistungen. http://portal.dimdi.de/de/hta/htaberichte.

2. Parker WH, Jacoby V, Shoupe D, Rocca W: Effect of bilateral oophorectomy on women's long-term health. Women's Health (London) 2009; 5: 565-76.

3. Nathanson KL, Domchek SM: Therapeutic approaches for women predisposed to breast cancer. Annu Rev Med 2011; 62: 295-306.

4. Burges A, Schmalfeldt A: Ovarian cancer: diagnosis and treatment. Dtsch Arztebl Int 2011; 108(38): 635-41.

\section{Dr. med. Alexander Burges}

Klinik und Poliklinik für Frauenheilkunde und Geburtshilfe - Großhadern Alexander.Burges@med.uni-muenchen.de

\section{Prof. Dr. med. Barbara Schmalfeldt}

Frauenklinik der TU München, Klinikum rechts der Isar

\section{Conflict of Interest Statement}

Professor Schmalfeld has received honoraria for speaking from Essex, GlaxoSmithKline, Fresenius Biotech, Amgen, Lilly Germany, Roche International, and Boehringer. Dr Burges declares that no conflict of interest exists. 